\title{
Micro 2C-injection moulding - investigations on interface performance
}

E. Honza ${ }^{*}$, A. Klein*, K. Plewa*, V. Piotter ${ }^{\star}$, C. Tuinea-Bobe**, B. Whiteside**

*Karlsruhe Institute of Technology, Institute for Applied Materials (IAM-WPT)

${ }^{* *}$ University of Bradford, School of Engineering, Design and Technology, Bradford, United Kingdom
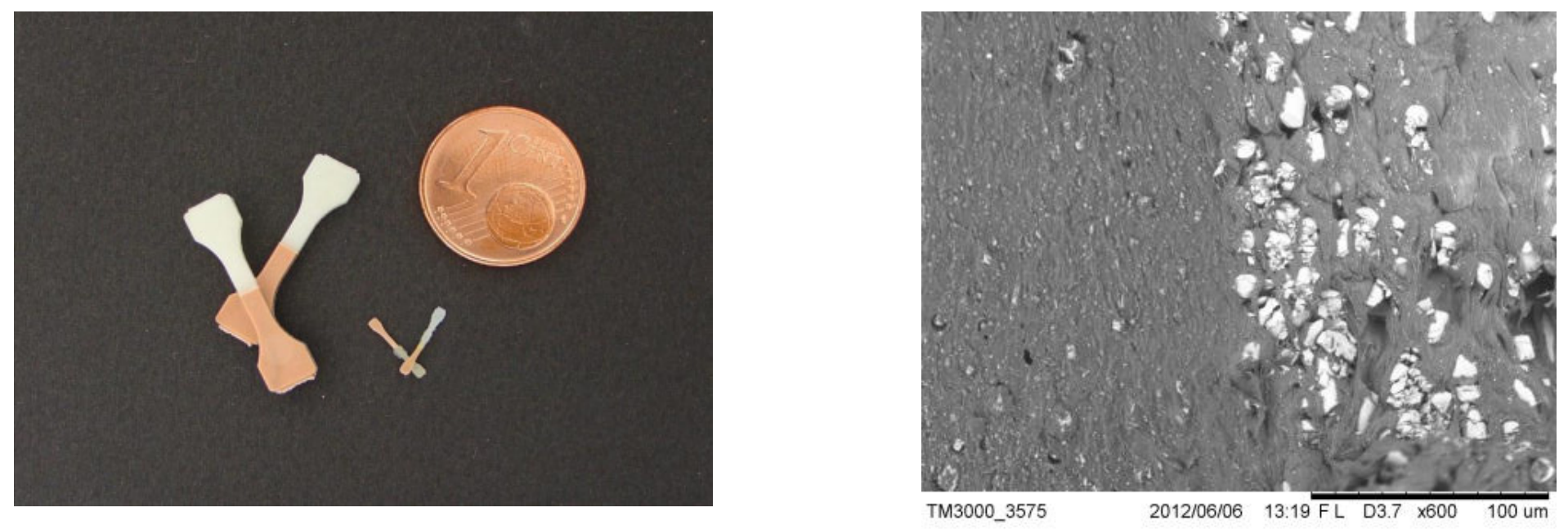


\section{Outline of the talk}

1. A new approach for $2 \mathrm{C}-\mu \mathrm{IM}$

2. Realisation of the new approach for $2 \mathrm{C}-\mu \mathrm{IM}$

3. Investigations and results of the test specimen, especially on interface performance

4. Summary \& Outlook 


\section{A new approach for $2 \mathrm{C}-\mu \mathrm{IM}$}

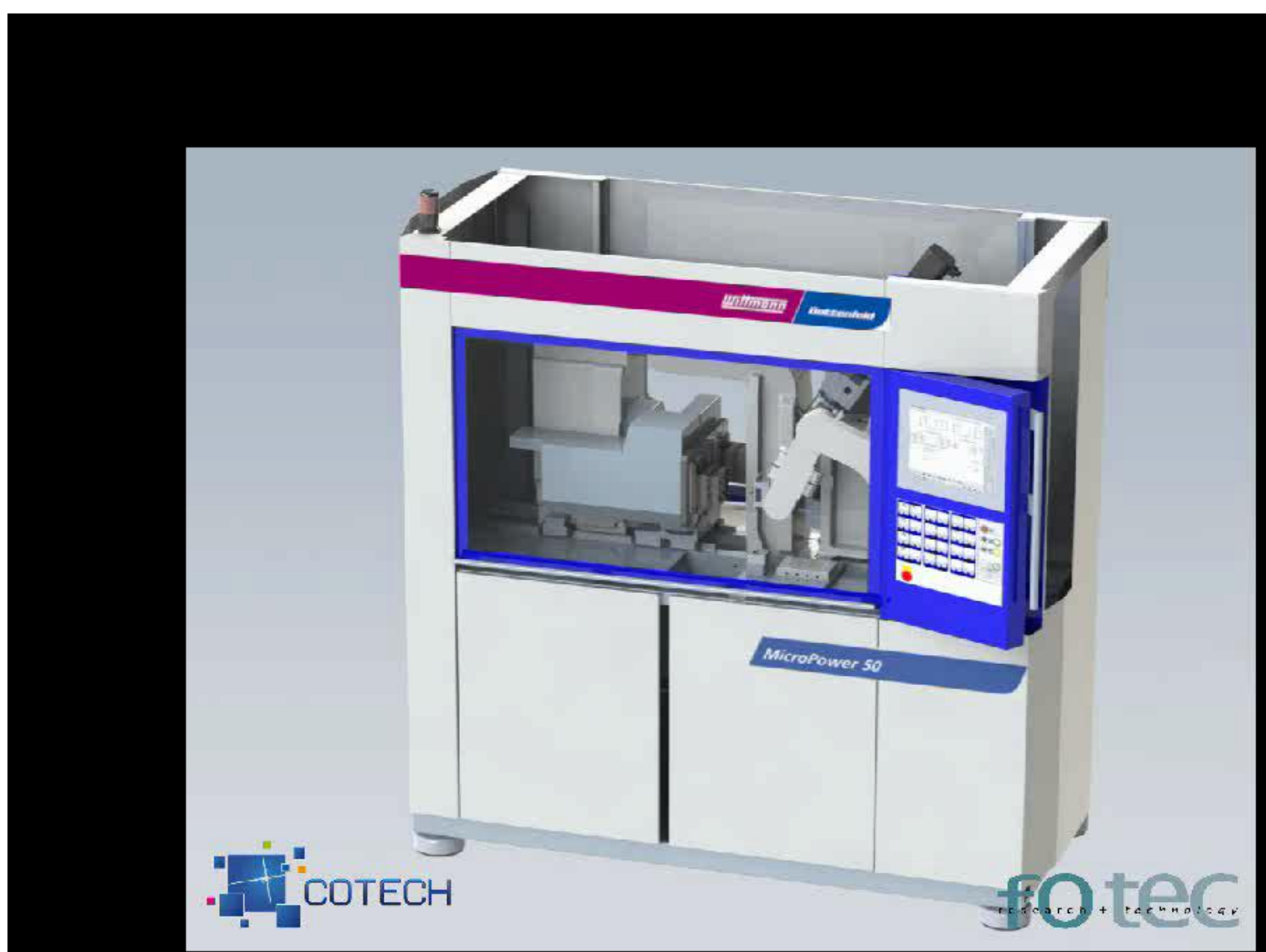




\section{A new approach for $2 \mathrm{C}-\mu \mathrm{IM}$}

$>$ biggest advantage: the possibility to use two machine units as individual machines if no multi-component parts has to be produced

$>$ flexibility

$>$ higher degree of utilisation

$>$ realisation of the individual processing for each component (tool temperature, isothermic and/or variothermic processing, back pressure and /or compression, etc.)

$\rightarrow$ main question: differences between new approach for $2 C-\mu l M$ and "classic" 2C- $\mu$ IM 


\section{Realisation of the new $2 \mathrm{C}-\mu \mathrm{IM}$}

two versions of process sequence (tensile bar as test specimen) :

$>$ "classical" $2 \mathrm{C} \mu$-IM:

injection of the second component immediately $(0.2 \mathrm{~s})$

after removing slide bar

$>$ approximation of the new $2 \mathrm{C} \mu-\mathrm{IM}$ :

1) The tempered tool closes

2) Injection of the first component PA

3) The slide bar opens after the chosen stand-by time (5 or 10s)

$\sim$ transfer time

4) Injection of the second component TPE

5) After the cooling time the tool opens

6) Ejection of the tensile bar 


\section{Realisation of the new $2 \mathrm{C}-\mu \mathrm{IM}$}

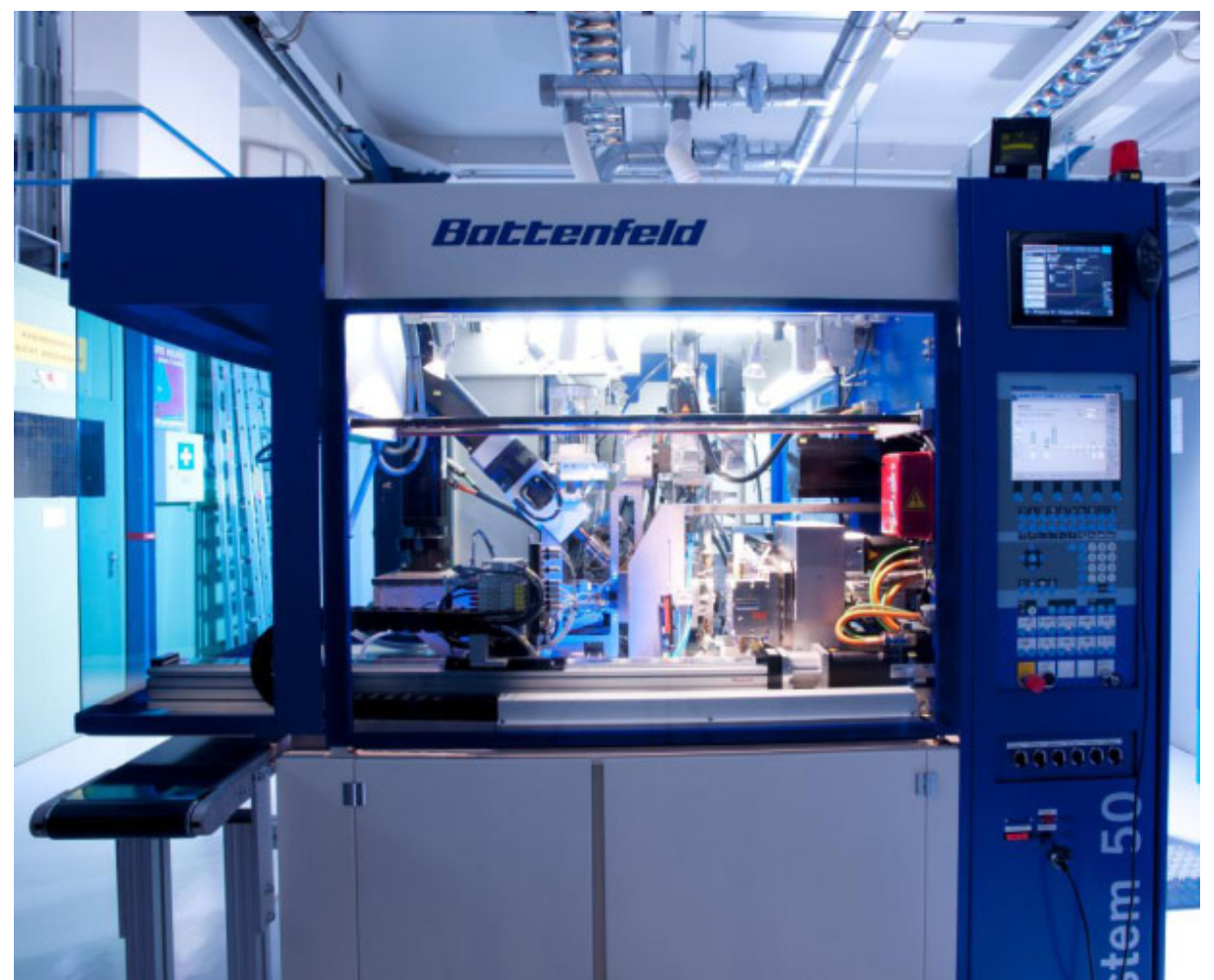

Advanced Wittmann Battenfeld Microsystem 50-2K machine with $L$-position of the second injection unit at KIT
2C- tool manufactured by Technical University of Denmark (DTU):

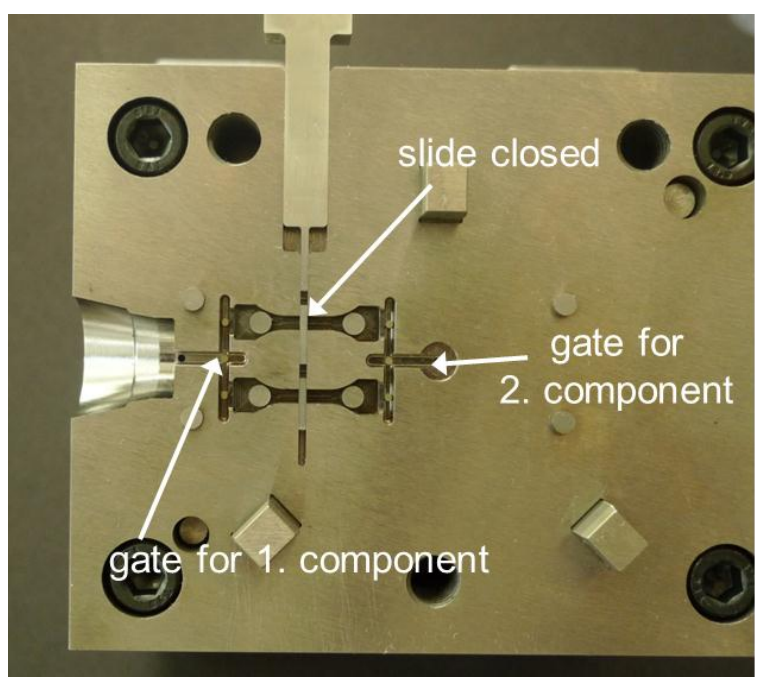

ejection side 


\section{Realisation of the new $2 \mathrm{C}-\mu \mathrm{IM}$}

\section{Test specimen:}
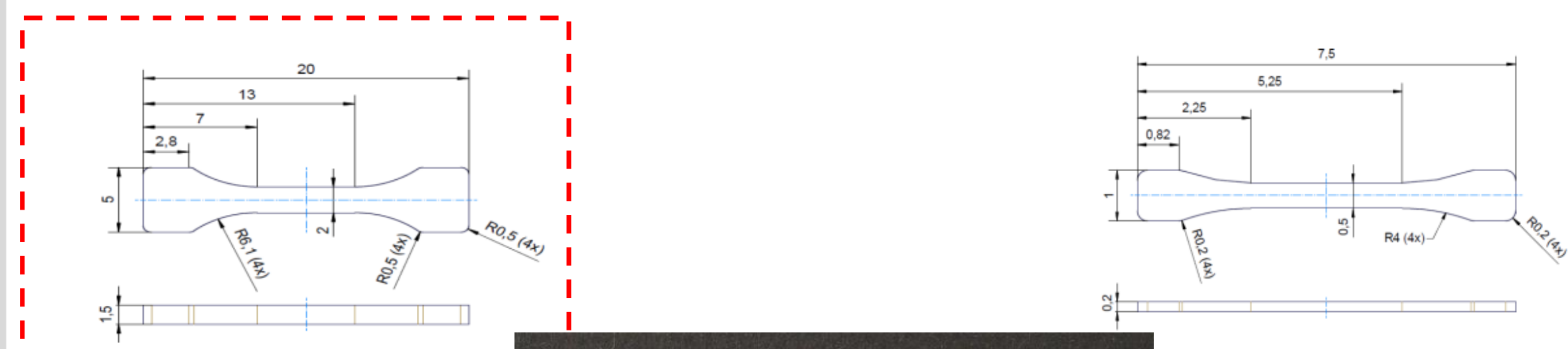


\section{Realisation of the new $2 \mathrm{C}-\mu \mathrm{IM}$}

\section{Materials:}

\begin{tabular}{|c|c|c|}
\hline Material & Trade name & Distributor \\
\hline PA 6.6 & Ultramid A3EG10 & BASF (coloured red, supplied by Sonion) \\
\hline TPE & Lifoflex UV 63.01B045 & Müller Kunststoffe \\
\hline & THERMOFLEX 60A3.4 & Plastic Technologie Service \\
\hline & THERMOFLEX 60A3.4HS & Plastic Technologie Service \\
\hline & Santoprene 8291-60B500 & ExxonMobil chemical \\
\hline
\end{tabular}

\section{Performing:}

$>$ tool temperature: $70^{\circ} \mathrm{C}$ (maximum for TPE's) and $80^{\circ} \mathrm{C}$ (minimum for PA)

$>$ further process parameters were adjusted to the particular materials

$>$ determination: tool temperature with enormous influence on the realisation of the bonding quality 


\section{Investigations and Results}

Tensile tests at Freiburg University:

$>$ testing set-up consists of a modified Zwick Z010 tensile testing machine

$>$ testing of the tensile bars are in relation to DIN 53504

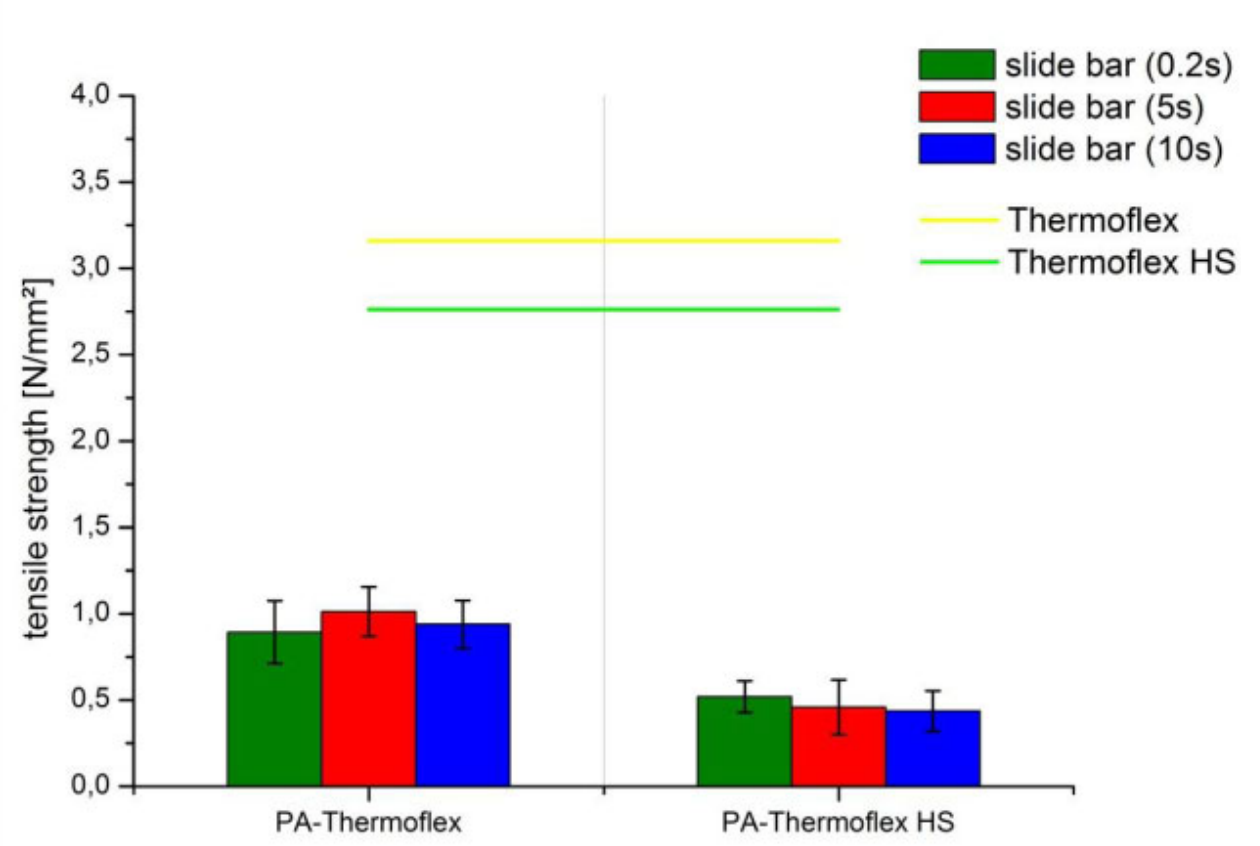

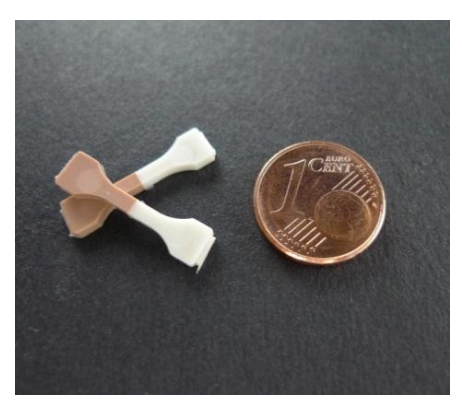

PA-Lifoflex

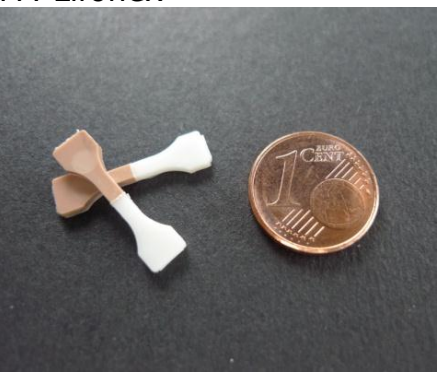

PA-Thermoflex HS

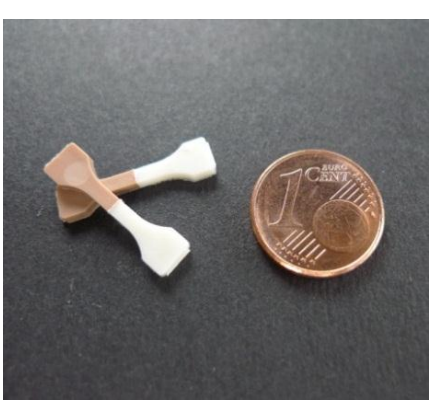

PA-Santoprene

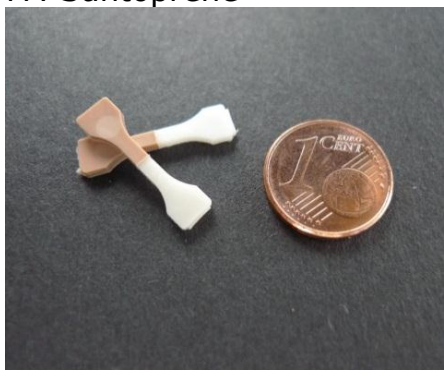

PA-Thermoflex 


\section{Investigations and Results}

Cryogenic cutting and microscopic investigation at Bradford University:

$>$ investigation of the interface between PA and TPE of two versions of process sequence

$>$ preparation: clamped, immersed in a liquid nitrogen bath (40 sec) and sectioned in two half by a very sharp scalpel blade

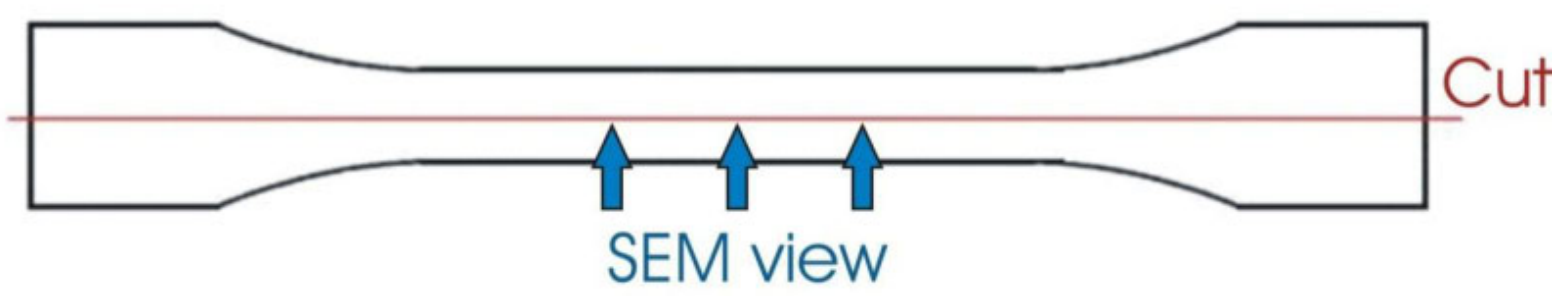

Cutting site of tensile bars for interface investigation 


\section{Investigations and Results}

\section{":"COTECH}

Interface: PA - Lifoflex
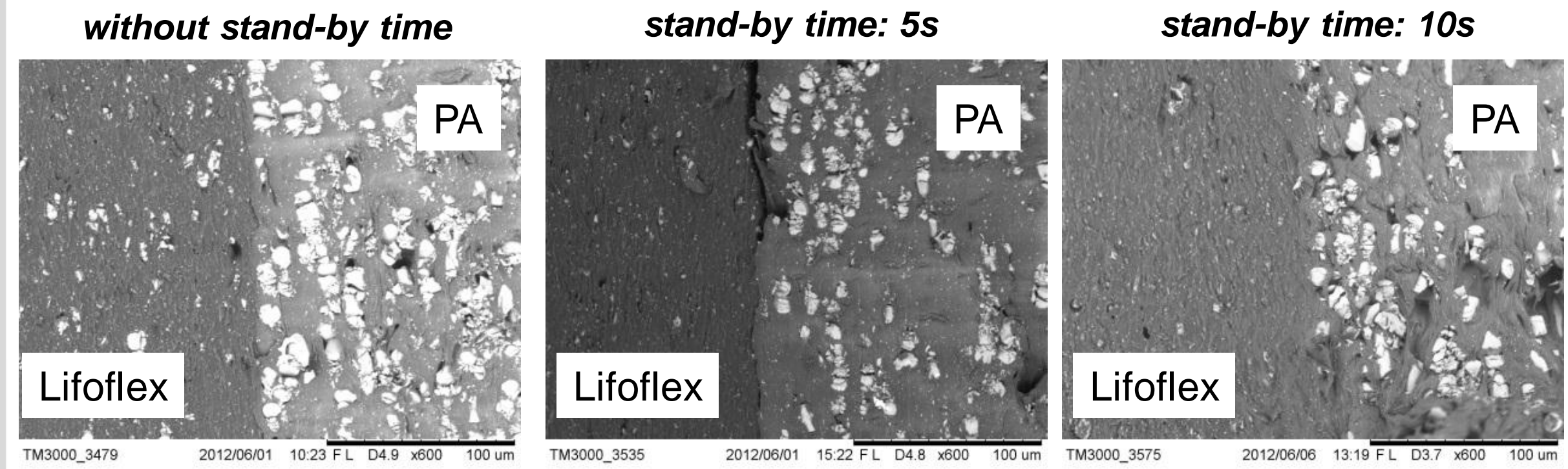

$>$ no significant differences could be determined

$>$ increase of the stand-by time does not show severe anomalies at the interface 


\section{Investigation and Results}

Interface: PA - Thermoflex
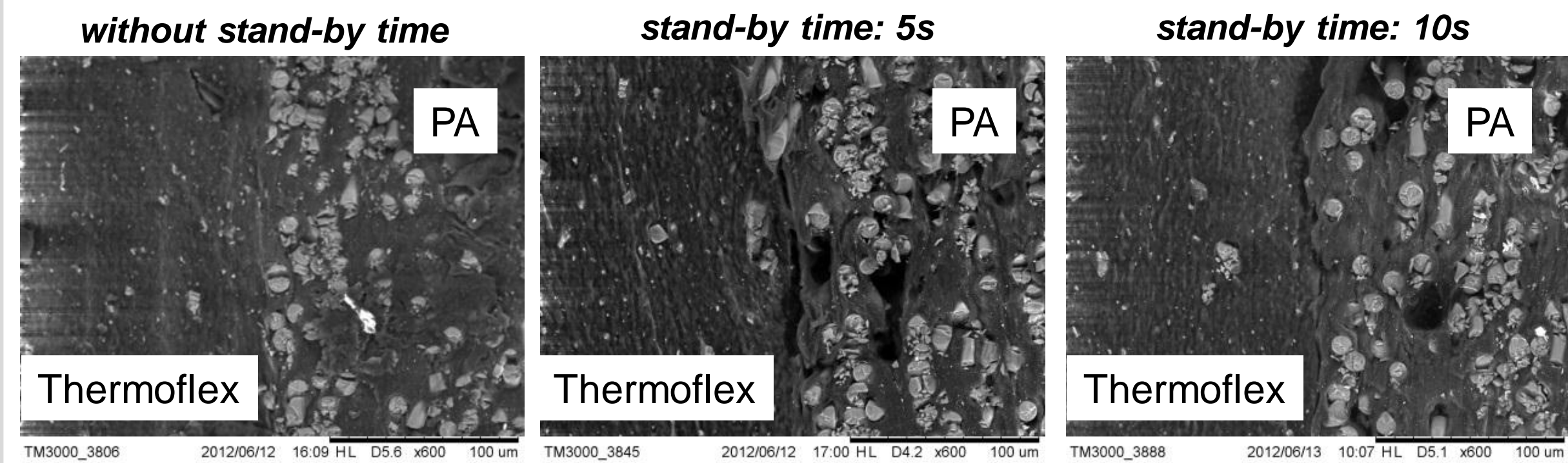

$>$ interface look more discontinuous if the slider was removed after $5 \mathrm{~s}$ or $10 \mathrm{~s}$ 


\section{Investigations and Results}

Interface: PA - Santoprene

without stand-by time

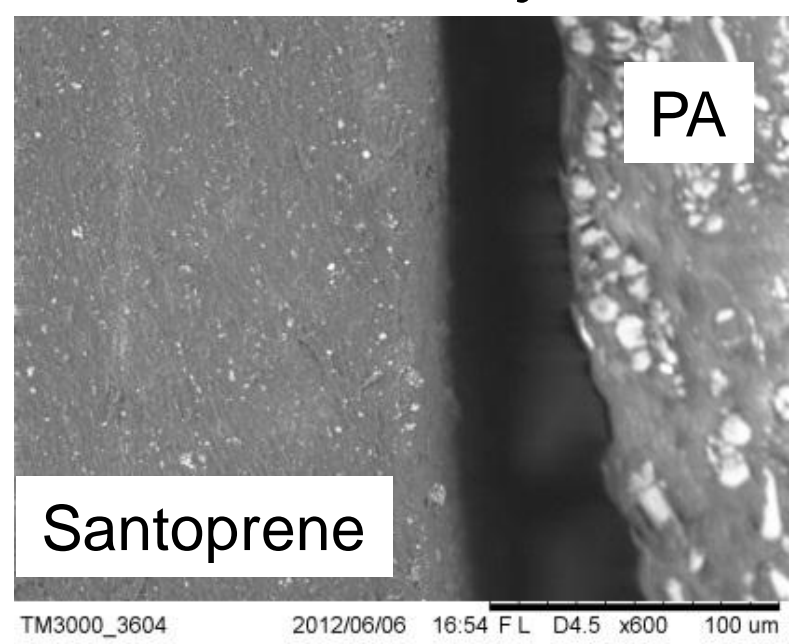

stand-by time: $5 s$

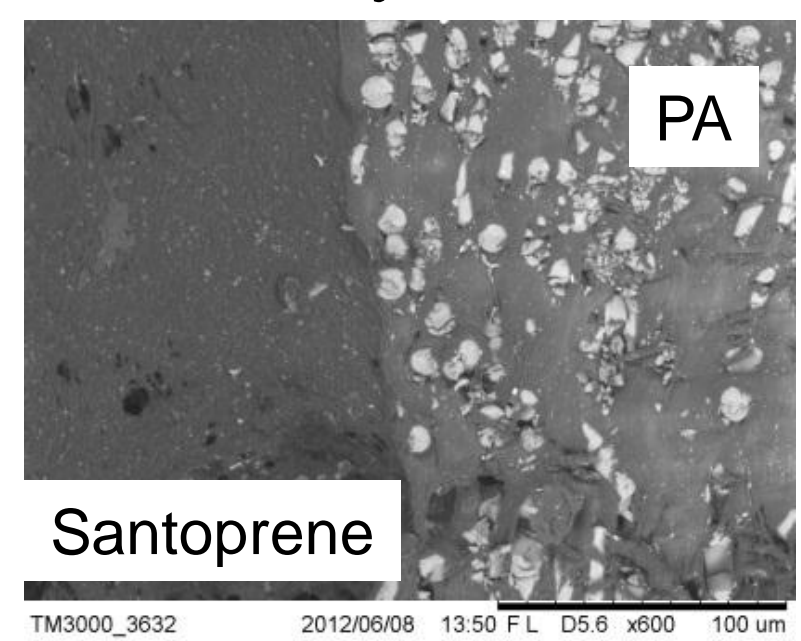

stand-by time: 10s

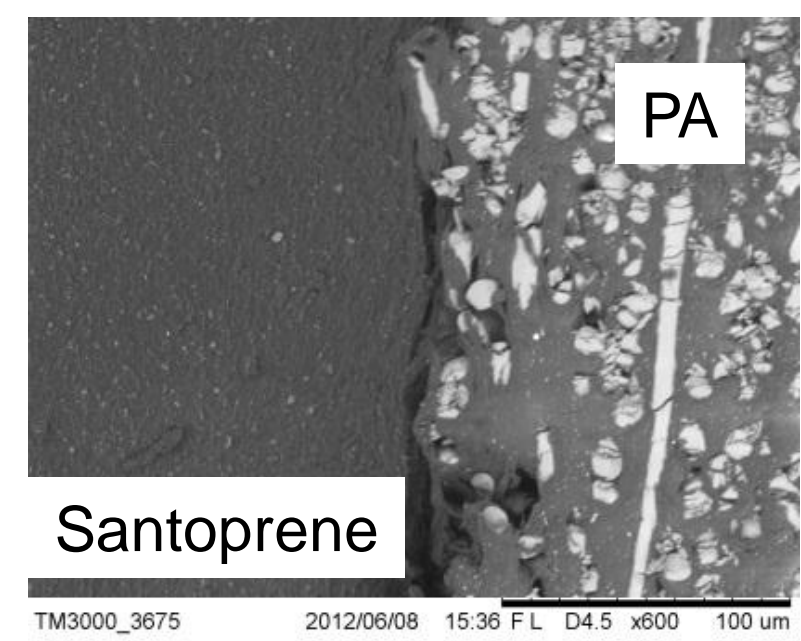

$>$ classic $2 \mathrm{C} \mu$-IM: powerful dislocation from the interface; during the cryogenic cut disconnection of the two materials

$>$ using the new $2 \mathrm{C}-\mu \mathrm{IM}$ process conduct, however, a certain bonding could be achieved 


\section{Summary and Outlook}

$>$ the microscopic investigations showed an indefinite characteristic

$>$ on the other hand, this phenomenon seems to depend much more on the particular material pairings than on the way of process conduct

the new $2 C-\mu I M$ variant shows no significant inferiority compared to classic 2C $\mu-I M$

due to the economic advantages of the new process conduct an increased utilization can be expected 


\section{Acknowledgement}

$>$ funding by the European Commission (IP 214491-2 "COTECH") as well as by the Karlsruhe Nano Micro Facility (KNMF)

> Department of Microsystem Engineering (IMTEK) at the University of Freiburg, Department of Mechanical Engineering of the Technical University of Denmark (DTU), and to the Centre for Polymer Micro and Nano Technology of the University of Bradford 